УДК 538.9

\title{
Effect of Anisotropy on the Transport Properties of Layered High-temperature Superconductors with Extended Magnetic and Nonmagnetic Defects
}

\author{
Vladimir A. Kashurnikov* \\ Anastasiia N. Maksimova ${ }^{\dagger}$ \\ Igor A. Rudnev $\ddagger$ \\ Dmitry S. Odintsov ${ }^{\S}$ \\ Institute of Laser and Plasma Technologies \\ National Research Nuclear University (Moscow Engineering Physics Institute) \\ Kashirskoe shosse, 31, Moscow, 115409 \\ Russia
}

Received 05.12.2016, received in revised form 14.12.2017, accepted 20.03.2018

Transport properties of anisotropic superconductor with point, columnar and columnar tilted defects have been analyzed using Monte-Carlo method. It was shown that for columnar tilted defects the critical current dependence on anisotropy $\gamma$ weakens as $\gamma$ increases and vanishes at certain $\gamma$. The S-type nonlinearity of current-voltage characteristics has been shown for three-dimensional vortex system in presence of ferromagnetic defects.

Keywords: layered superconductors, vortex pinning, magnetic nanoparticles, Monte Carlo method. DOI: 10.17516/1997-1397-2018-11-2-227-230.

Vortex pinning in type-II superconductors defines magnetic and transport properties and can be enhanced by introducing point or extended magnetic and nonmagnetic defects. In order to obtain the higher value of critical current, the interaction between vortices and different types of pinning centers is extensively studied. Pinning by extended columnar defects in Bi2212 and YBCO has been widely studied [1,2]. In [2], transport properties of BSCCO single crystal in presence of three-dimensional system of splayed columnar defects has been studied. It was demonstrated that a splayed configuration provides a larger improvement in pinning properties than the configuration with columnar defects parallel to the c-axis at low temperatures.

To enhance vortex pinning, magnetic nanoparticles as point defects can be used due to additional interaction energy between vortex and magnetic moment of the particle [3-5]. Spherical and ellipsoidal magnetic nanoparticles have been used as pinning centers in [3-4], the interaction energy between vortex and nanoparticle was obtained in the framework of London approximation. The authors of [5] numerically demonstrated some new effects, such as S-type nonlinearity of current-voltage characteristic due to magnetization reversal of nanoparticles.

The aim of this paper is to analyse numerically the effect of anisotropy on critical current in presence of columnar tilted defects and to study transport properties of three-dimensional superconductor with nanosized ferromagnetic defects with alternating magnetic moment.

\footnotetext{
*vakashurnikov@mail.ru

${ }^{\dagger}$ nastymaksimova@yandex.ru

¥iarudnev@mephi.ru

$\S$ dodintsov@mail.ru

(c) Siberian Federal University. All rights reserved
} 


\section{Model and simulation method}

The simulations were made within a three-dimensional model of a layered high-temperature superconductor (HTSC) [6] by using Monte-Carlo algorithm. The model is a general case of the two-dimensional model [7-9] and takes into account various types of in-plane interactions and the inter-plane interaction. A vortex line is represented as a stack of interacting planar vortices. To describe the inter-plane interaction between pancakes we used the equations for electromagnetic and Josephson potentials obtained by Goldschmidt and Tyagiin [10-11]. See [7-9] for details.

The size of the nanoparticle is much less than the average size of ferromagnetic domain so that a magnetic moment of each particle has a constant absolute value and variable direction. For simulations, we considered superconductor and ferromagnetic nanoparticles as a self-consistent system. This method has previously been reported in [5].

We obtained then current-voltage characteristics by using method developed in [7] for three-dimensional $\mathrm{Bi}_{2} \mathrm{Sr}_{2} \mathrm{CaCu}_{2} \mathrm{O}_{8-\delta}$ superconducting slab. Magnetic moments of defects are $\mu \sim 10^{3}-10^{4}$ Bohr magnetons, which is typical for ferromagnetic materials. We considered a three-dimensional superconducting slab which contains $\mathrm{N}_{\mathrm{L}} \sim 10$ superconducting $\mathrm{CuO}_{2}$ layers.

\section{Results}

Let us analyse now the effect of tilted defects for HTSC with different anisotropy. Fig. 1 represents the critical current $\mathrm{j}_{\mathrm{c}}$ of two superconductive slabs with different concentration of defects as a function of tilt angle. It can be seen that jc strongly depends on tilt angle for weakly anisotropic superconductors and is independent of $\alpha$ for high $\gamma$. We suppose this effect to be explained via the peculiarities of pinning pancake stacks by point pinning centers. When anisotropy is low, the vortex line is rigid and tilted defect does not pin full vortex line since the bending of vortex requires energy greater than effective depth of defects potential well.

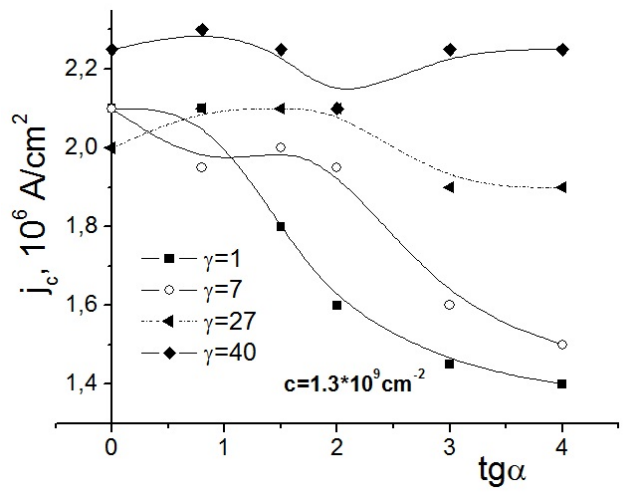

a)

Fig. 1. Critical current as a function of $\alpha . \mathrm{c}$ is a concentration of defects

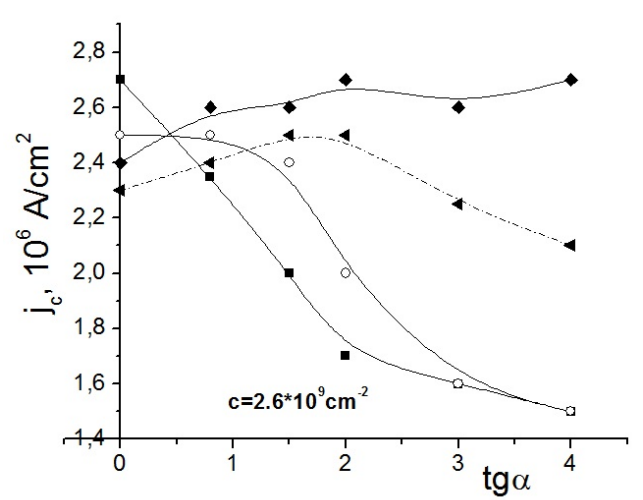

b)

Addition of magnetic moment to the point pinning center changes significantly the process of magnetization by transport current. In particular, the S-type nonlinearity (previously reported and explained by us for two-dimentional system [5]) is also observed in a more realistic threedimensional case (Fig. 2 (a)).

We calculated then critical current of the superconductor in presence of external magnetic field tilted relative to c-axis. This issue is widely studied (see, for example, [12] — BSCCO, 
a)

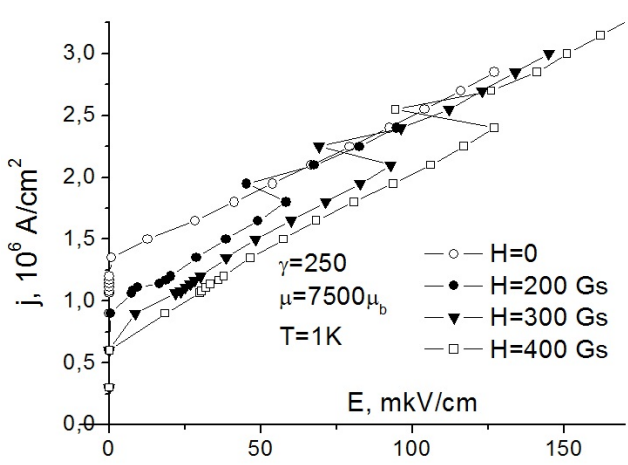

b)

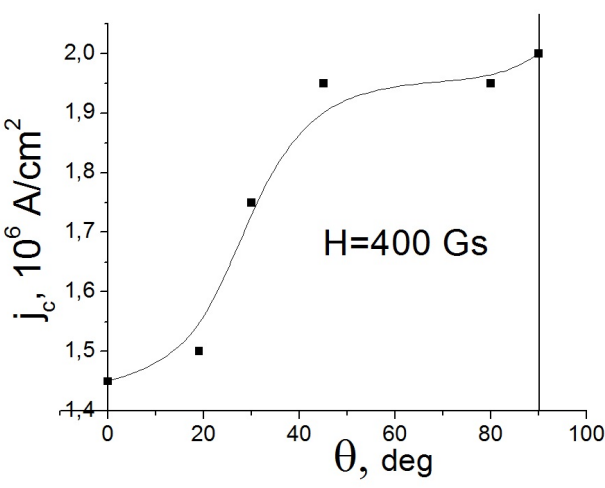

Fig. 2. Current-voltage characteristics of HTSC with ferromagnetic defects in external dc magnetic field (a); Magnetic field angular dependence of $j_{c}(b)$

[13] - YBCO). We introduce the description of tilted field into Monte Carlo algorithm via simulation of two interacting vortex systems: Abrikosov vortex lattice (associated with parallel to c-axis component of magnetic field) and Josephson vortex lattice (associated with perpendicular component) [14]. Abrikosov vortices are perpendicular to the superconducting $\mathrm{CuO}_{2}$ layers and Josephson vortices are parallel to the layers. Fig. 2 (b) represents a critical current as a function of $\theta$ - an angle between magnetic field and c-axis. One can easily see, that obtained numerically critical current is higher if magnetic field is parallel to $\mathrm{CuO}_{2}$ plane which is typical for anisotropic layered HTSC, but without sharp peak typical for YBCO [13].

\section{Conclusion}

To conclude, we obtained the decreasing dependencies of critical current on the tilt angle for HTSC with columnar tilted defects. The S-type nonlinearity of current-voltage characteristics of HTSC with ferromagnetic defects in external dc magnetic field was demonstrated in threedimensional case. Magnetic field angular dependence of $\mathrm{j}_{\mathrm{c}}$ in tilted magnetic field was obtained, the results are in qualitative agreement with experiment. This fact indicates that our simplified $3 \mathrm{D}$ simulation model can provide an adequate result in case of tilted magnetic field.

Research was done with the financial support of RFBR (grant no. 15-02-02764)

\section{References}

[1] N.M.Strickland et al., Flux pinning by discontinuous columnar defects in $74 \mathrm{MeV} \mathrm{Ag-}$ irradiated $\mathrm{YBa}_{2} \mathrm{Cu}_{3} \mathrm{O}_{7}$ coated conductors, Physica C, 469(2009), 2060-2067.

[2] V.A.Shaidiuk et al., Pinning efficiency of splayed columnar defects in Bi-2212 single crystal: Evidence of a cage pinning effect, Journal of Phys. and Chem. of Solids, 72(2011), 541-544.

[3] A.Snezhko, T.Prozorov, R.Prozorov, Magnetic nanoparticles as efficient bulk pinning centers in type-II superconductors, Phys. Rev. B, 71(2005), 024527.

[4] C.Huang, H.Yong, Y.Zhou, Effect of magnetic nanoparticleson the mechanical properties of type-II superconductors, Acta Mechanica Solida Sinica, 27(2014), no. 1, 65-72. 
[5] V.A.Kashurnikov et al., Domain of a magnetic flux in superconductors with ferromagnetic pinning centers, Phys. of the Solid State, 57(2015), no. 9, 1726-1734 (in Russian).

[6] W.E.Lawrence, S.Doniach, in Proceedings of LT 12, Kyoto, (1970), edited by E.Kanda (Keigaku, Tokyo, 1971), 361.

[7] D.S.Odintsov, I.A.Rudnev, V.A.Kashurnikov, Vortex System Dynamics and Energy Losses in a Current-Carrying 2D Superconducting Wafer, JETP, 103(2006), no. 1, 66-76.

[8] I.A.Rudnev, D.S.Odintsov, V.A.Kashurnikov, Critical current suppression in high-Tc superconductors and its dependence on the defects concentration, Phys. Lett. A, 372(2008), 3934-3936.

[9] D.S.Odintsov, I.A.Rudnev, V.A.Kashurnikov, On the Mechanisms of Transport Losses in High-Temperature Superconductors, JETP, 105(2007), 253-255.

[10] Sandeep Tyagi and Yadin Y. Goldschmidt, Flux melting in $\mathrm{Bi}_{2} \mathrm{Sr}_{2} \mathrm{CaCu}_{2} \mathrm{O}_{8-\delta}$ : Incorporating both electromagnetic and Josephson couplings, Phys. Rev. B, 70(2004), 024501.

[11] Yadin Y. Goldschmidt and Sandeep Tyagi, Interpolation of the Josephson interaction in highly anisotropic superconductors from a solution of the two-dimensional sine-Gordon equation, Phys. Rev. B, 71(2005), 014503.

[12] Guo Min Zhang, Liang Zhen Lin, Li Ye Xiao, Yun Jia Yu, A theoretical model for the angular dependence of the critical current of BSCCO/Ag tapes, Physica C, 390(2003), 321-324.

[13] Y. Zhang et al., Magnetic field orientation dependence of flux pinning in ( $\mathrm{Gd}, \mathrm{Y}) \mathrm{Ba}_{2} \mathrm{Cu}_{3} \mathrm{O}_{7-x}$ coated conductor with tilted lattice and nanostructures, Physica C, 469(2009), 2044-2051.

[14] A. E. Koshelev, Vortex-chain phases in layered superconductors, Phys. Rev. B, 71(2005), 174507.

\title{
Влияние анизотропии на транспортные свойства слоистого высокотемпературного сверхпроводника с магнитными и немагнитными протяженными дефектами
}

\author{
Владимир А. Кашурников \\ Анастасия Н. Максимова \\ Игорь А. Руднев \\ Дмитрий С. Одинцов \\ Институт лазерных и плазменных технологий \\ Национальный исследовательский ядерный университет "МИФИ" \\ Каширское шоссе 31, Москва, 115409 \\ Россия
}

Методом Монте-Карло проанализированы транспортные свойства анизотропного сверхпроводника с точечными, колумнарными и колумнарными наклонными дефектами. Показано, что в случае колумнарных наклонных дебектов зависимость критического тока от анизотропии $\gamma$ ослабевает с ростом $\gamma$ и при определенном $\gamma$ исчезает совсем. Показано наличие S-образной нелинейности вольт-амперной характеристики для трехмерной вихревой системы с ферромагнитными дефектами.

Ключевые слова: слоистье сверхпроводники, пиннинг вихрей, магнитнъе наночастиць, метод Монте-Карло. 